\title{
Article
}

\section{Development of Two-way Volume Equation for Bamboo, Phyllostachys nigra}

\author{
Akio Inoue ${ }^{* 1}$, Shingo Sakamoto ${ }^{* 1}$, Haruka Kitazato ${ }^{* 1}$ and Kotaro Sakuta ${ }^{* 2}$
}

\begin{abstract}
A two-way volume equation for one of the three major useful bamboos in Japan, Phyllostachys nigra var. henonis, is developed and the goodness of fit is evaluated using the data collected from two different districts. The model used here was the generalized theoretical volume equation. The normal form-factors at 0.7 and 0.8 for $P$. nigra were steady at 0.622 and 0.558 , respectively. Inserting these values into the generalized theoretical volume equation enabled us to determine the coeficients of the volume equation. Although the estimated apparent culm volume was significantly smaller than actual one, the relative mean error of the estimated volume was comparatively small. The volume equation for Phyllostachys bambusoides Sieb. et Zucc. could be directly applied to $P$. nigra, whereas that for Phyllostachys pubescens Mazel et Houz. could not. This fact indicated that the inter-species characteristics of culm form should be carefully considered when evaluating the bamboo resources by the volume equation. In conclusion, the generalized theoretical volume equation would be effective when evaluating the resources and comparing the stand productivity for $P$. nigra.
\end{abstract}

Keywords: apparent culm volume; bamboo, culm form, generalized theoretical volume equation, normal form-factor

\section{INTRODUCTION}

Bamboo is highly versatile and rapidly renewable, long been used as a timber alternative for flooring, construction, furniture, charcoal, crafts and food (Buckingham et al., 2011). In addition, recent technological developments cleared way for bamboo to be used extensively in manufacturing the reconstituted panel and board products, fuel, pulp and paper (DRusT et al., 2004). ZHoU et al. (2005) also reviewed the environmental functions of bamboo forests such as soil conservation and carbon fixation. Because of these economic and environmental values, bamboo has received increasing attention over the last two decade in Asia, Africa and Latin America (RUz-PEREZ et al., 2001) and is expected to contribute to development in bamboo growing rural areas as "poor man's timber" (Lou et al., 2010).

In Japan, there are more than 150,000 hectares of

Corresponding author: Akio Inoue

*1 Laboratory of Forest Ecology, Faculty of Environmental and Symbiotic Sciences, Prefectural University of Kumamoto, Kumamoto 862-8502, Japan

E-mail: iakio@pu-kumamoto.ac.jp (A. Inoue)

${ }^{2}$ Faculty of Agriculture, Kyushu University, Fukuoka 821-8581, Japan bamboo forests (Lovovikov et al., 2007). New shoots occur naturally and annually without planting or seeding in bamboo forests, and they reach the mature size in a matter of two or three months (ZHou et al., 2005). Therefore, bamboo has a potential as plentiful biomass resources in Japan, but not used effectively (MnNaMi and SAKA, 2005). In order to establish the effective utilization of bamboo resources and sustainable management of bamboo forests, reliable data and information with regards to their resources are required (KLEINN and MoRALEs, 2006). Culms are major component among aboveground parts of bamboo (e.g., SuzunI and Uchimura, 1980; YEN et al., 2010; YEN and LEE, 2011), and are more useful compared to branches and leaves. Culm volume is therefore one of the most important information when evaluating bamboo resources (INOUE et al., 2011; SUGA et al., 2011) and comparing stand productivities (AOKI, 1955; CAMARGO and KLEINN, 2010). However, there is still a lack of availability of basic models for estimating apparent culm volume, i.e., the total culm volume including the hollow part, or wood volume, i.e., the volume of the woody walls of the culms (KIEINN and MoRAIEs, 2006; CAMARGO and KIEINN, 2010).

Phyllostachys nigra var. henonis, which is native to China (Lr et al., 2005), is one of the three major useful bamboos in Japan along with Phyllostachys pubescens Mazel et Houz. and Phyllostachys bambusoides Sieb. et Zucc. (Uchmura, 2009). $P$. nigra was probably introduced from China about 800 years ago, and have been traditionally used for edible shoots and industrial arts (SuzUKI and NAKAGOSHI, 2011). Although $P$. nigra occupies only about $0.4 \%$ of the total bamboo growing 
area in Japan (UCHIMURA, 1980), its area exceed more than 20\% of bamboo growing area in a certain district (e.g., FoRESTRY and Fisheries Department of Kumamoto Prefecture, 2005). This implies that $P$. nigra might be useful biomass resources in its much growing area. However, studies on $P$. nigra are extremely scarce, which involve the culm form (OTA, 1950), productivity (SUzunI and UCHMURA, 1980), amounts of litter fall and sheaths (WATANABE, 1983), fuel properties (ScuRLock et al., 2000), growth behavior (Li et al., 2005), stand dynamics (SAROINSONG et al., 2006) and spatial pattern (SAROINSONG et al., $2007)$.

In previous studies (INOUE et al., 2011; SUcra et al. 2011), the two-way volume equations for $P$. pubescens and $P$. bambusoides were derived so that the apparent culm volume can be estimated from diameter at breast height (dbh) and culm height. INOUE et al. (2011) found that there was a need for distinguishing the volume equation among these bamboo species, suggesting that the volume equation for $P$. nigra may also be different from those for the two species. However, to our knowledge, there have been no models for evaluating the culm volume of $P$. nigra. It is also unknown whether the volume equation for the two species can be directly applied to $P$. nigra. For the effective utilization and sustainable management of $P$. nigra, it is necessary to develop a model for evaluating its culm volume.

The objective of the present study was thus to develop the two-way volume equation for estimating apparent culm volume for $P$. nigra. First, the two-way volume equation was determined using the generalized theoretical volume equation (INoue et al., 2011; Suga et al., 2011). Second, the goodness of fit and applicability of the determined volume equation were evaluated based on the data collected from two different districts. Third, the volume equation for $P$. nigra was compared with those for other bamboo species, i.e., $P$. pubescens and $P$. bambusoides, determined in previous studies (INOUE et al., 2011; SUGA et al., 2011).

\section{MATERIAIS AND METHODS}

Data
The data used in this study was collected from two stands of $P$. nigra in Ito campus of Kyushu University (ITO: $33^{\circ} 36^{\prime}$ $\mathrm{N}, 130^{\circ} 13^{\prime} \mathrm{E}, 60 \mathrm{~m}$ a.s.l.) in Fukuoka City and in the campus of Fukuoka University of Education (FUE: $33^{\circ} 48^{\prime} \mathrm{N}, 130^{\circ} 36^{\prime}$ E, $50 \mathrm{~m}$ a.s.1.) in Munakata City, Fukuoka Prefecture, western Japan. These stands were about $40 \mathrm{~km}$ away from each other. The average annual temperature and annual rainfall for the last decade at the nearest observatory were, respectively, $16.1{ }^{\circ} \mathrm{C}$ and $1.677 \mathrm{~mm}$ for $\mathrm{TTO}$ and $15.6{ }^{\circ} \mathrm{C}$ and $1,640 \mathrm{~mm}$ for FUE, indicating that these areas will be a favorable condition for the growth of bamboo (Scurlock et al., 2000). Both stands were very dense and their canopies were closed, and hence no other vegetation was found on the forest floors.

In each stand, healthy and living sample culms with various sizes were felled at ground level for direct measurement of height and diameter in October 2011. The number of samples was 100 for ITO and 50 for FUE. The culm height was measured directly with a tape measure to the nearest tenth of a meter. The external culm diameter at 1.2 $m$ height above ground level (dbh) and ten successive points were measured with a digital caliper to the nearest tenth of a centimeter. The measurement points were located along the culm at equal intervals of one tenth of the direct measured culm height (relative height: $0.1,0.2, \ldots, 1.0$ ). General description of the samples is given in Table 1.

\section{Analysis Methods}

The apparent culm volume for each sample was computed by the sectional measurement method (WEST, 2004). The sample culms collected from ITO were randomly bisected into two sets of data, i.e., modeling and test data $(n=50$ for each set). The samples from FUE were also pooled for the test data $(n=50)$, so that an applicability of the determined volume equation can be evaluated. For the modeling data, the normal form-factors for the ten relative heights, i.e., $\lambda_{0.1}, \lambda_{0.2}, \ldots, \lambda_{1.0}$, were computed, and then their averages and coefficients of variation $(\mathrm{CV})$ were calculated. The dependence of each normal form-factor on the culm sizes, i.e., $\mathrm{dbh}$ and culm height, was analyzed with Spearnan's correlation coefficient by rank test. From the viewpoints of the smallness of $\mathrm{CV}$ and

Table 1 General description of Phyllostachys wigra sample culms

\begin{tabular}{llll} 
& Diameter at breast height $(\mathrm{cm})$ & Culm height $(\mathrm{m})$ & Apparent culm volume $\left(\mathrm{dm}^{3}\right)$ \\
\hline MO $(n=100)$ & & & 2.4 \\
Average & 2.7 & 6.3 & 1.7 \\
Standard derivation & 0.7 & 1.4 & 7.5 \\
Maximum & 4.3 & 9.3 & 0.2 \\
Minimum & 1.1 & 3.1 & 1.8 \\
Median & 2.6 & 6.1 & \\
FUE $(n=50)$ & & & 3.6 \\
Average & 2.9 & 7.3 & 3.1 \\
Standard derivation & 1.1 & 2.0 & 12.2 \\
Maximum & 4.9 & 11.3 & 0.1 \\
Minimum & 0.9 & 2.7 & 2.6 \\
Median & 2.9 & 7.5 & \\
\hline
\end{tabular}


independence on the culm sizes, the steady normal formfactors at two different relative heights were selected. The coefficients of the volume equation for $P$. nigra were then determined by substituting the averages of the steady normal form-factors and their relative heights into the following generalized theoretical volume equation:

$$
v=\frac{\lambda_{j} \pi d_{\mathrm{b}}^{2} h}{4\left[\left(1-h_{\mathrm{b}} / h\right) / j\right]^{\log \left(\lambda_{\mathrm{k}} / \lambda_{j}\right) / \log (j / i)}}
$$

where $v$ : apparent culm volume; $d_{\mathrm{b}}$ : diameter at breast height; $h$ : culm height; $h_{\mathrm{b}}$ : breast height ( $=1.2 \mathrm{~m}$ in this study); $\lambda_{i}$ and $\lambda_{j}$ averages of the steady normal form-factors at relative height $i$ and $j$, respectively. For the detail of the derivation of Eq. 1, see INOUE et al. (2011) or SUGA et al. (2011).

For the test data from ITO and FUE, the apparent culm volume for each sample culm was estimated by inserting the measured $\mathrm{dbh}$ and culm height into the determined volume equation. For each district, the goodness of fit of the volume equation was evaluated by the mean error (ME), relative mean error (\%ME), root mean square error (RMSE) and relative root mean square error (\%RMSE). The estimated apparent culm volume was compared with the actual one with Wilcoxon signed-rank test. All statistical procedures were performed with the R software (R DEVELOPMENT CORE TEAM, 2006).

\section{RESULTS}

Normal Form-factors for P. nigra

Fig. 1 depicts the average and coefficient of variation (CV) of the normal form-factors for $P$. nigra. The average of the normal form-factor decreased from culm tip to base. CV of the normal form-factor was the smallest at $0.8 \mathrm{in}$ relative height, and gradually increased from there toward both ends of culm. $\mathrm{CVs}$ of the normal form-factors from 0.5 to 0.9 in relative height were less than $10 \%$, indicating that the variations in these normal form-factors were smaller than those in other form-factors.

The correlation coefficients between normal form-factors and culm sizes are given in Fig. 2. Spearman's correlation coefficient by rank test indicated that $\lambda_{0.2}, \lambda_{0.7}$ and $\lambda_{0.8}$ were not significantly correlated with diameter at breast height $(r$ $=-0.106, P=0.463$ for $\lambda_{0.2} ; r=-0.224, P=0.119$ for $\lambda_{0.7}$ and $r=$ $0.001, P=0.993$ for $\lambda_{0.8}$ ), whereas $\lambda_{0.3}, \lambda_{0.2}, \lambda_{0.2}$ and $\lambda_{0.8}$ were not significantly correlated with the culm height $(r=0.207, P$ $=0.149$ for $\lambda_{0.1} ; r=-0.027, P=0.850$ for $\lambda_{0.2} ; r=-0.184, P=0.201$ for $\lambda_{0.7}$ and $r=0.081, P=0.578$ for $\left.\lambda_{0.8}\right)$. On the other hand, other normal form-factors were significantly correlated with either diameter at breast height and culm height $(P<0.05)$.

\section{Determination and Goodness of Fit of the Volume Equation}

Because of the smaller variation and independency on culm sizes, $\lambda_{0.7}$ and $\lambda_{0.8}$ were selected to determine the coefficients of the volume equation. Relationships of $\lambda_{0.7}$ and $\lambda_{0.8}$ to culm sizes are shown in Fig. 3 , indicating that these normal form-factors were independent of the culm sizes. Substituting their averages, i.e., $\lambda_{0.7}=0.622$ and $\lambda_{0.8}=0.558$, and the relative heights into Eq. 1, we obtained the following two-way volume equation for $P$. nigra:

$$
v=\frac{0.622 \pi d_{\mathrm{b}}^{2} h}{4\left[\left(1-h_{\mathrm{b}} / h\right) / 0.7\right]^{0.813}}
$$

Fig. 4 compares the estimated and actual apparent culm volume for P. nigra collected from ITO and FUE. The mean error (ME), relative mean error (\%ME), root mean square error (RMSE) and relative root mean square error (\%RMSE) are summarized in Table 2. For ITO, there was a slightly significant difference between estimated and actual apparent culm volume $(P<0.01)$, with ME and RMSE being $-0.092 \mathrm{dm}^{3}$ and $0.013 \mathrm{dm}^{3}$, respectively. The estimated culm volume for FUE was also significantly smaller than the actual one $(P<$


Fig. 1 Average and coefficient of variation (CV) of normal form-factors for Phyllostachys nigra 


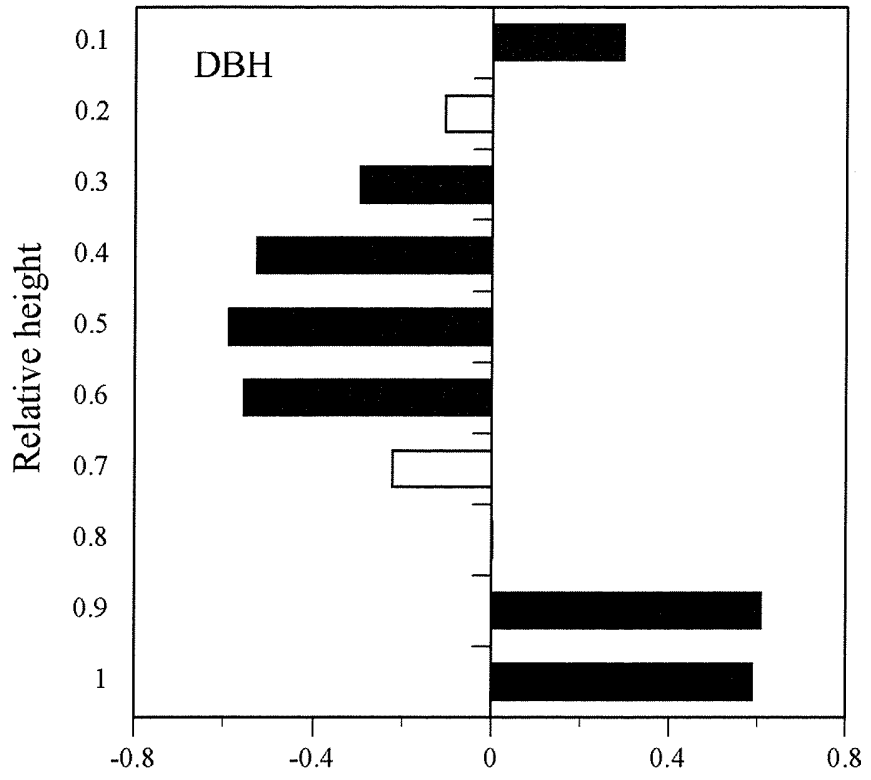

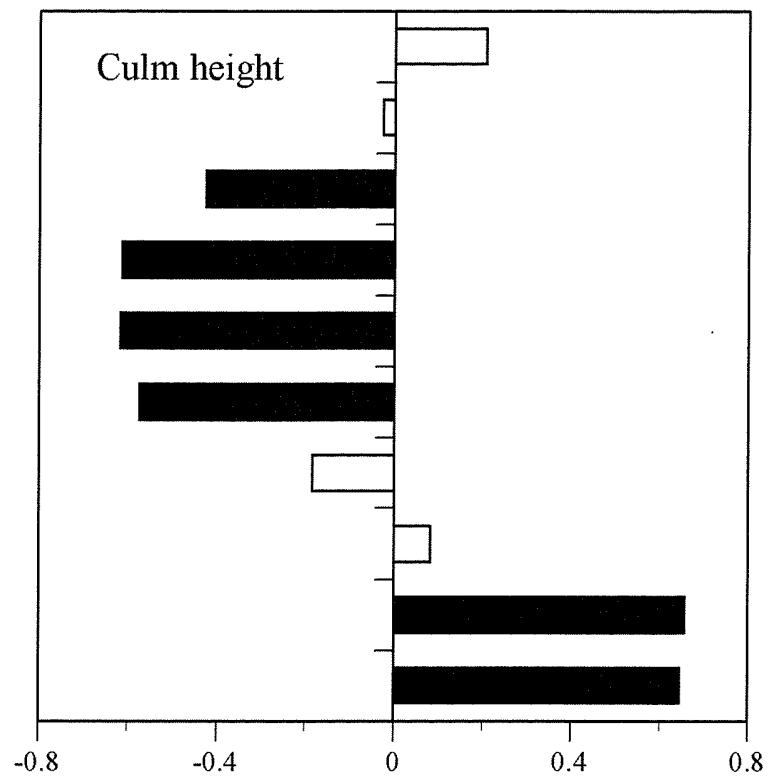

Correlation coefficient between normal-form factor and culm size

Fig. 2 Correlation coefficients between normal form-factors and culm sizes for Phyllostachys nigra. The black and white bars indicate significant and insignificant correlation coefficients at $5 \%$ level, respectively.

0.001), with ME and RMSE being $-0.232 \mathrm{dm}^{3}$ and $0.460 \mathrm{dm}^{3}$, respectively. \%ME and \%RMSE were, respectively, $-3.936 \%$ and $0.557 \%$ for ITO and $-6.422 \%$ and $12.703 \%$ for FUE.

\section{DISCUSSION}

Culm Form of $P$. nigra

In this study, the generalized theoretical volume equation was applied to the development of the two-way volume equation for $P$. nigra. The coefficients of this volume equation are determined based on the analysis of the normal formfactors. As shown in Fig. 1, the coefficients of variation (CV) of the normal form-factors from 0.5 to $0.9 \mathrm{in}$ relative height were less than 10\%. Similar findings were reported for P. pubescens (SUGA et al., 2011) and P. bambusoides (INoue et al., 2011). This supports that these normal form-factors will be effective in determining the coefficients of the generalized theoretical volume equation for bamboo species (INove et al., 2011).

The normal form-factors at 0.6 and 0.9 in relative height, $\lambda_{0.6}$ and $\lambda_{0,6}$, for $P$. pubescens and $P$. bambusoides were not correlated with culm sizes (INove et al., 2011; SUGA et al., 2011). By contrast, these normal form-factors for $P$. nigra were significantly correlated with culm sizes, and $\hat{\lambda}_{4,7}$ and $\lambda_{0.8}$ were not alternatively correlated (see Fig. 2). The result suggests that the steady normal form-factors would vary with bamboo species. Our data also demonstrated that $\lambda_{0.5}$ was negatively correlated with culm sizes, whereas $\lambda_{0.9}$ was positively correlated. Since $\lambda_{0,6}$ was larger than $\lambda_{0,9}$ (see Fig. 1), the difference between $\lambda_{0,6}$ and $\lambda_{0,9}$ becomes smaller with an increasing in culm sizes. This fact means that the culm form for $P$. nigra becomes non-tapering with the culm sizes, whereas $\lambda_{0.7}$ and $\lambda_{0.8}$ are steady at constant levels.

Goodness of Fit of the Determined Volume Equation

Table 2 Mean error (ME), relative mean error (\%ME), root mean square error (RMSE) and relative root mean square error (\%RMSE) between estimated and actual apparent culm volume for Phyllostachys nigra

\begin{tabular}{|c|c|c|c|c|}
\hline & $\mathrm{ME}\left(\mathrm{dm}^{3}\right)$ & \%ME (\%) & RMSE $\left(\mathrm{dm}^{3}\right)$ & \#RMSE $(\%)$ \\
\hline \multicolumn{5}{|c|}{ Estimation from the volume equation for Phyllostachys nigra (Eq. 2 in the text) } \\
\hline $\operatorname{IrO}(n=50)$ & -0.092 & -3.936 & 0.013 & 0.557 \\
\hline FUE $(n=50)$ & -0.232 & -6.422 & 0.460 & 12.703 \\
\hline \multicolumn{5}{|c|}{ Estimation from the volume equation for Phyllostachys pubescens (Eq. 3 in the text) } \\
\hline ITO $(n=50)$ & -0.185 & -7.881 & 0.386 & 16.493 \\
\hline FUE $(n=50)$ & -0.484 & -13.380 & 0.815 & 22.509 \\
\hline \multicolumn{5}{|c|}{ Estimation from the volume equation for Phyllostachys bambusoides (Eq. 4 in the text) } \\
\hline ITO $(n=50)$ & 0.049 & 2.097 & 0.229 & 9.791 \\
\hline FUE $(n=50)$ & -0.013 & -0.349 & 0.297 & 8.212 \\
\hline
\end{tabular}



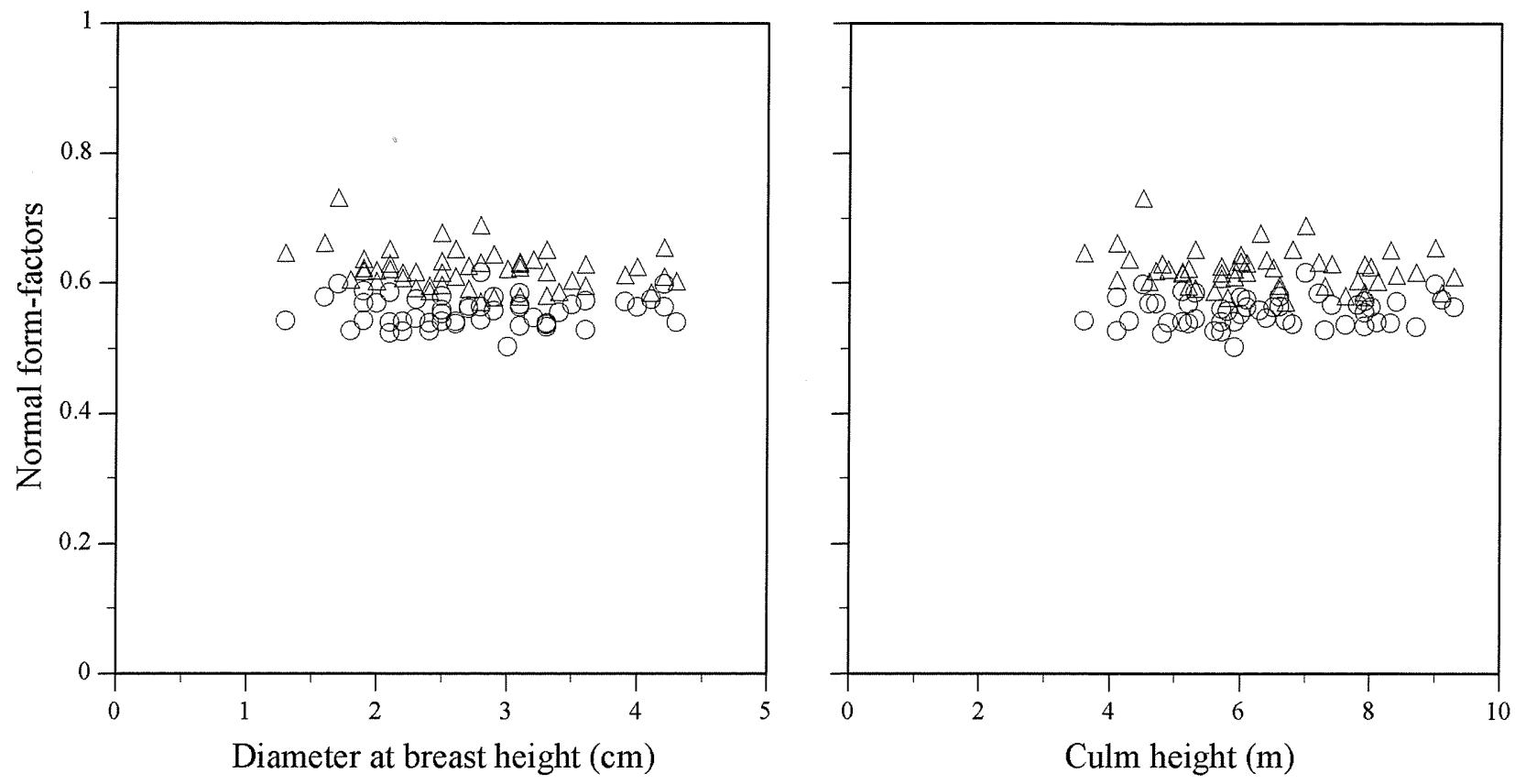

Fig. 3 Relationships of normal form-factors to diameter at breast height and culm height for Phyllostachys nigra. The triangle and circle indicate the normal form-factors at 0.7 and 0.8 in relative height, respectively.
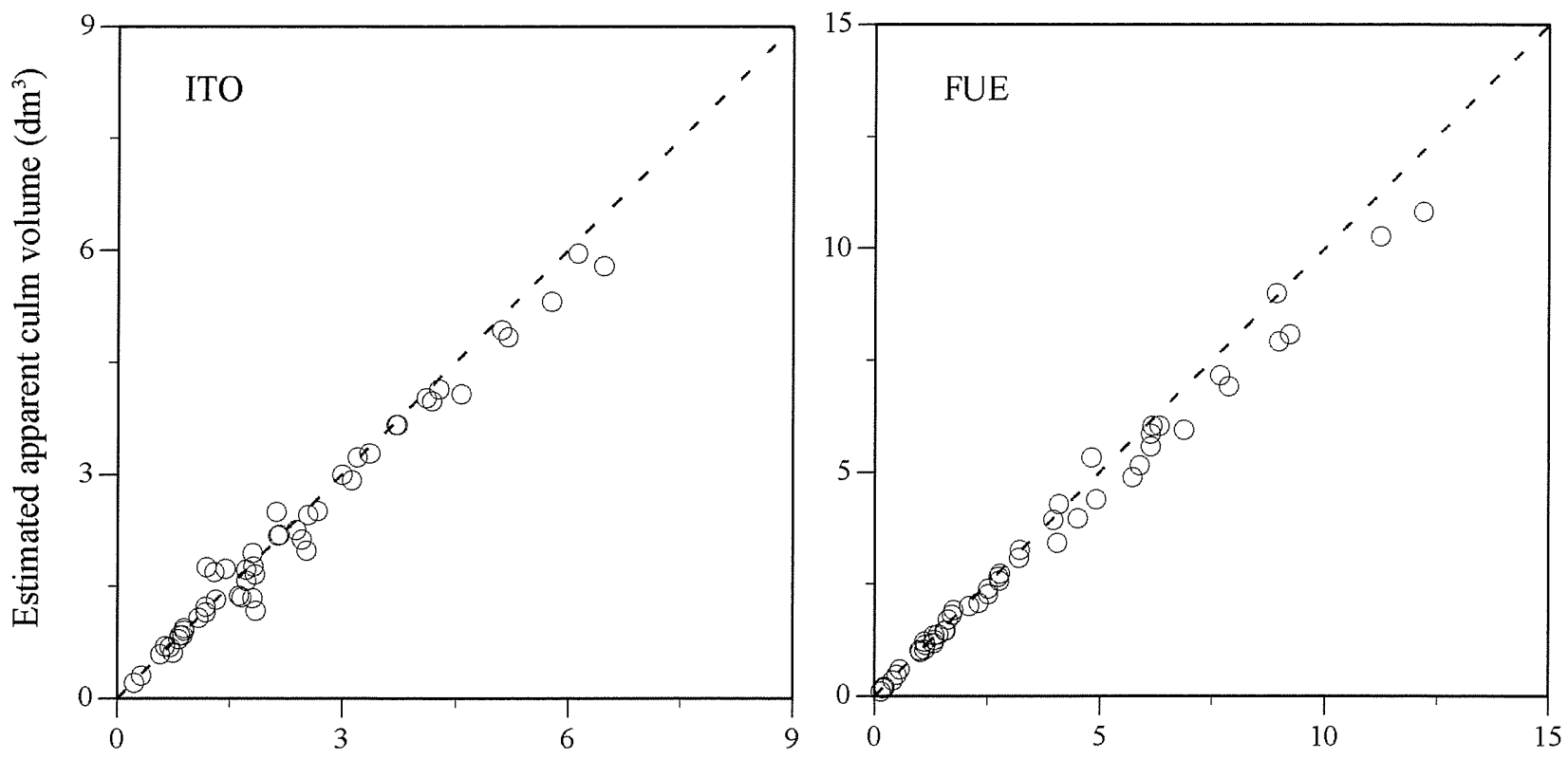

Actual apparent culm volume $\left(\mathrm{dm}^{3}\right)$

Fig. 4 Comparison of the estimated and actual apparent culm volumes for Phyllostachys nigra. The broken line indicates 1:1.

The generalized theoretical volume equation used in this study was originally proposed as the theoretical volume equation for estimating the stem volume of coniferous tree species (INOUE and KurOKAWA, 2001). INOUE et al. (2011) and SUGA et al. (2011) generalized this volume equation to apply to the bamboo species as well as the coniferous tree species. INOUE and KUROKAWA (2001) reported that the relative mean error of the theoretical volume equation was $1.543 \%$ for Cryptomeria japonica D. Don and $8.402 \%$ for Chamaecyparis obtusa Endl. INove et al. (2002) also found that the relative mean error of the volume equation ranged from-1.091\% to $11.400 \%$ for Larix kaempferi grown in four different districts. In addition, INOUE (2006) applied the volume equation to $C$. japonica grown in three districts with different management regimes, and reported that relative mean error ranged from $0.923 \%$ to $15.908 \%$. Furthermore, the empirical volume equations used widely produced a comparable goodness of fit of the theoretical volume equation (INOUE, 2006; INOUE and KUROKAWA, 2001; INOUE et al., 2002). INOve (2006) applied the generalized theoretical volume equation to $P$. pubescens, with 
the relative mean error being $0.172 \%$. For $P$. bambusoides, SUGA et al. (2011) also reported that the relative mean error of the generalized theoretical volume equation ranged from -5.558 to $1.122 \%$.

The result of this study showed that the estimated apparent culm volume was significantly smaller than actual one for both districts, with the relative mean error being $-3.936 \%$ for ITO and $-6.422 \%$ for FUE (see Fig. 4 and Table 2). There are no clear difference in relative mean error of the estimated volume between the previous studies and this study. Therefore, the significant difference between the estimated and actual apparent culm volume for $P$. nigra does not always deny the effectiveness of the determined generalized theoretical volume equation, Eq. 2. When estimating the volume for bamboo and coniferous tree species, it should be noted that the generalized theoretical volume equation would produce a comparable relative mean error found in this study and previous ones, i.e., about $\pm 10 \%$ (INOUE, 2006; INOUE and KUROKAWA, 2001; INOUE et al., 2002, 2011; SUGA et al., 2011).

\section{Comparison of the Volume Equations}

The generalized theoretical volume equation has been applied to other bamboo species as follows:

$$
v=\frac{0.908 \pi d_{\mathrm{b}}^{2} h}{4\left[\left(1-h_{\mathrm{b}} / h\right) / 0.6\right]^{1.742}}
$$

for P. pubescens (SugA et al., 2011) and

$$
v=\frac{0.737 \pi d_{\mathrm{b}}{ }^{2} h}{4\left[\left(1-h_{\mathrm{b}} / h\right) / 0.6\right]^{0.761}}
$$

for P. bambusoides (INOUE et al., 2011). For the test data of $P$. nigra, the apparent culm volume was estimated with these volume equations. The statistics of the goodness of fit are summarized in Table 2. For both districts, the estimated apparent culm volume was significantly smaller than actual one when applying Eq. 3 for $P$. pubescens $(P<0.01$ for ITO and $P<0.001$ for FUE). By contrast, there was no significant difference between estimated and actual apparent culm volume when applying Eq. 4 for $P$. bambusoides to $P$. nigra from FUE $(P=0.717)$. Although there was a significant difference between estimated and actual apparent culm volume for $P$. nigra from ITO $(P<0.05)$, the relative mean error was comparatively small $(2.097 \%)$. This result suggests that the common volume equation, Eq. 2 or 4 , could be applied to $P$. nigra and $P$. bambusoides, whereas the different volume equation, Eq. 3 , should be applied to $P$. pubescens.

This failure of diversion of Eq. 3 will be caused by the difference in the culm form between the bamboo species: The averages of $\lambda_{0.6}$ and $\lambda_{0.9}$ for $P$. nigra were, respectively, 0.743 and 0.541 , whereas these normal form-factors varied with culm sizes (see Fig. 2). By contrast, the averages of $\lambda_{0.6}$ and $\lambda_{0.9}$ were, respectively, steady at 0.908 and 0.448 for $P$. pubescens (SUGA et al., 2011) and at 0.736 and 0.543 for P. bambusoides (INOUE et al., 2011). The difference between $\lambda_{0,6}$ and $\lambda_{0.9}$ is smaller for $P$. nigra than $P$. pubescens, indicating that $P$. nigra holds a non-tapering culm form compared to $P$. pubescens. For this reason, the apparent culm volume for $P$. nigra having more non-tapering culm form will be underestimated when applying the volume equation for $P$. pubescens having more tapering form. Similar result was reported between $P$. pubescens and $P$. bambusoides (INove et al., 2011). By contrast, no clear differences in the normal form-factors were found between $P$. nigra and $P$. bambusoides, suggesting that the culm form of $P$. nigra would be similar to that of $P$. bambusoides. Because of the similarity of the culm form, the apparent culm volume of $P$. nigra could be successfully estimated by applying Eq. 4 for $P$. bambusoides. These facts indicate that the species characteristics of culm form should be carefully considered when evaluating the bamboo resources by the volume equations.

\section{Recommendation for Future Studies}

In the world, there are 1250 bamboo species within 75 genera, and most of them would be overlooked biomass resources (ScuRLocK et al., 2000). Although the utilization and management of bamboo require information on the amount of the resources (KIEINN and MoRALEs, 2006), it is impractical to separate the volume equation by each bamboo species. In reality, various bamboo species are classified into several groups based on the patterns of their culm forms, and then the volume equations should be prepared for each group. For instance, $P$. nigra and $P$. bambusoides are ascribed as the same group of bamboo and the common volume equation, i.e., Eq. 2 or 4 , is applied to these species. By contrast, P. pubescens should be distinguished from $P$. nigra and $P$. bambusoides, and it is necessary to apply the different volume equation, i.e., Eq. 3.

Various measures have been proposed and used for quantifying the stem form of a tree (e.g., INOUE, 2005). Among them, the normal form-factors used in this study might be one of the most effective measures for classifying various bamboo species into several groups, since their steady values can be directly used for determining the coefficients of the generalized theoretical volume equation. From this viewpoint, there is a need for further studies on the inter-specific variation in normal form-factors of culms across a wide range of bamboo species.

\section{ACKNOWLEDGEMENTS}

The authors wish to sincerely thank Drs. Takeshi OHucH and Kenji HrRAO for their consent and support for the research in Fukuoka University of Education. Field assistance was provided by the students of the Laboratory of Forest Ecology, Faculty of Environmental and Symbiotic Sciences, Prefectural University of Kumamoto, whose help is greatly appreciated.

\section{LITERATURE CITED}

Aoki, T., (1955): On the volume table of Madake (Phyllostachys reticulate $\mathrm{C}$. Koch) stem (in Japanese with English summary). Rep. Kyushu Univ. For. 5: $49-82$

Buchtngham, K., Jepson, P., Wu, L., RAO, I.V.R., JaAng, S., Llese, W., Lov, Y. and FU, M., (2011): The potential of bamboo is constrained by outmoded policy frames. AMB1O 40:544-548

CAmargo, J.C. and Klenn, C., (2010): Length curves and volume functions for guadua bamboo (Guadua angustifolia Kunth) for the 
coffee region of Colombia. Eur. J. For. Res. 129: 1213-1222

DURST, P.B., KLlmann, W. and Brown, C., (2004): Asia's new woods. J. For. 102: $46-53$

Forestry and Fisheries Department of Kumamoto Prefecture, (2005): A report of the effective utilization of abandoned bamboo forests in Kumamoto Prefecture* (in Japanese). Forestry and Fisheries Department of Kumamoto Prefecture, Kumamoto, 59pp

Inoue, A., (2005): Proposing new measures for quantifying a stem form (in Japanese with English summary). J. Jpn. For. Soc. 87: 133-137

INove, A., (2006): Application of theoretical volume equation to Japanese cedar. Ap. For. Sci. 15: 33-36

INOUE, A and KuROKAWA, Y., (2001): Theoretical derivation of a twoway volume equation in coniferous species (in Japanese with English summary). J. Jpn. For. Soc. 83: 130-134

Inove, A., Mrrsuda, M. and Wang, H., (2002): Application of theoretical volume equation to Larix leptolepis Gordon (in Japanese with English summary). Res. Bull. Tottori Univ. For. 27 : 23-29

Inoue, A., Sakamoto, S., Suga, H. and Kitahara, F., (2011): Estimation of culm volume for bamboo, Phyllostachys bambusoides, by two-way volume equation. Biomass Bioenergy 35: 2666-2673

Kleinn, C. and Morales-Hidalgo, D., (2006): An inventory of Guadua (Guadua angustifolia) bamboo in the coffee region of Colombia. Eur. J. For: Res. 125: 361-368

Li, Z, MAnfred, D. and Thomas, B., (2005): Growth behavior of Phyllostachys nigra var. henonis (Bambusoideae) in Central China. J. Forestry Res. 16: 163-168

Lov, Y., LI, Y., BucKingham, K., Henley, G. and Zhov, G., (2010): Bamboo and climate change mitigation. International Network for Bamboo and Rattan, Beijing, 47pp

Lobovikov, M., Paudel, S., Plazza, M., Ren, H. and Wu, J., (2007): World bamboo resources: A thematic study prepared in the framework of the global forest resources assessment 2005. FAO, Roma, 73pp

MNAMI, E. and SAKA, S., (2005): Biomass resources present in Japan: annual quantities grown, unused and wasted. Biomass Bioenergy 29: $310-320$

OTA, M., (1950): Studies on the properties of bamboo stem (Part 3): On the form of stem of MA-DAKE (Phyllostachys reticulata C. Koch), MOSO-CHKU (Phyllostachys edulis Riv.) and HA-CHIKU (Phyllostachys nigra var. Henonis Makino) (in Japanese with English summary). Bull. Kyushu Univ. For. 18: 37-58

R DEVELOPMENT CORE TEAM, (2006): R: A language and environment for statistical computing. http://www.R-project.org/ (Accessed on 25 Jan., 2012)

RutzPERE, M., FU, M., YANG, X. and Belcher, B., (2001): Bamboo forestry in China: Toward environmentally friendly expansion. J.
For. $99: 14-20$

Saronsong, F.B., Samamoto, K., Mini, N. and Yoshikawa, K., (2006): Stand dynamics of a bamboo forest adjacent to a secondary deciduous broad-leaved forest. J. Jpn. Soc. Reveget. Tech. 32: 1520

Saronsong, FB., Sakamoto, K., Hirobe, M., Mini, N. and Yoshtrawa, K., (2007): Spatial pattern of bamboo culms in an abandoned Phyllostachys nigra var. henonis stand. J. Jpn. Soc. Reveget. Tech. 33: 65-70

SCuRlock, J.M.O., DAYTON, D.C. and HAMEs, B., (2000): Bamboo: an overlooked biomass resource? Biomass Bioenergy 19: 229-244

Suga, H., Inoue, A. and KrTAHARA, F., (2011): Derivation of two-way volume equation for bamboo, Phyllostachys pubescens. J. For. Res. 16: $261-267$

SUZUKX, S. and NAKAGOSHI, N., (2011): Sustainable management of Satoyama bamboo landscapes in Japan. In: Hong S.K. Wu J., Kim J.E. and Nakagoshi N. (eds) Landscape Ecology in Asian Cultures, Springer, Tokyo: 211220

Suzuki, T. and UchmurA, E., (1980): Productivity of Hachiku (Phyllostachys puborula Makino) (in Japanese). Trans. Mtg. Jpn. For. Soc. 91: $327-328$

UChimurA, E., (1980): Bamboo cultivation. In: Lessard G. and Chouinard A. (eds) Bamboo Research in Asia. International Development Research Center, Ottawa: 151-160

UCHMURA, E., (2009): Utilization of bamboo resource into modern days* (in Japanese). Soshinsya, Tokyo, 217pp

Watanabe, M., (1983): Studies on the ecological characteristics of bamboo stand: Litter-fall and the amount of sheaths in Phyllostachys pubescens and Phyllostachys nigra var. henonis stands (in Japanese). Bamboo J. 1: 28-35

WEst, P.W., (2004): Tree and forest measurement. Springer, Berlin, $167 \mathrm{pp}$

YEN, T.M. and LEE, J.S., (2011): Comparing aboveground carbon sequestration between moso bamboo (Phyllostachys heterocycla) and China fir (Cunninghamia lanceolata) forests based on the allometirc model. For. Ecol. Manage. 261: 995-1002

YEN, T.M., J, Y.J. and LEE, J.S., (2010): Estimating biomass production and carbon storage for a fast-growing makino bamboo (Phyllostachys makinoi) plant based on the diameter distribution model. For. Ecol. Manage. 260: 339-344

Zhou, B., Fu, M., XIE, J., YANG, X. and LI, Z., (2005): Ecological functions of bamboo forests; research and application. J. Forestry Res. 16: 143-147

* These English titles are tentative translations by the authors of this paper from the original Japanese titles.

(Recieved 25 January 2012) (Accepted 9 February 2012) 